\title{
Pioglitazone in Clinical Practice: Where Are We Now?
}

\author{
Joytish Govindan · Marc Evans
}

To view enhanced content go to www.diabetestherapy-open.com

Received: November 14, 2011 / Published online: February 29, 2012

(c) The Author(s) 2012. This article is published with open access at Springerlink.com

\section{ABSTRACT}

Pioglitazone, a thiazolidinedione, improves insulin sensitivity and thus reduces blood glucose. Clinical trials have suggested potential cardiovascular outcome benefits in association with pioglitazone; however, safety concerns are mounting, with recent data suggesting a link between pioglitazone and an increased risk of bladder cancer. There is thus a growing focus on the risk-benefit profile of this agent and hence its potential role in the blood glucose-lowering treatment algorithm for people with type 2 diabetes. There are clear potential outcome benefits associated with pioglitazone. In this review, the authors focus on putting the true risk-benefit profile of

J. Govindan · M. Evans $(\varangle)$

Department of Diabetes, University Hospital

Llandough, Cardiff, Wales, UK

e-mail: marc.evans2@ntlworld.com

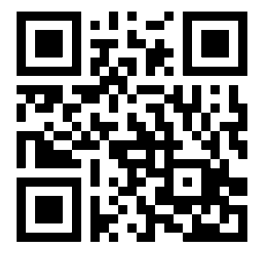

Enhanced content for this article is available on the journal web site: www.diabetestherapy-open.com pioglitazone into context based on critical appraisal of the currently available evidence.

Keywords: Bladder cancer; Pioglitazone; Thiazolidenidione; Type 2 diabetes

\section{INTRODUCTION}

Pioglitazone is the only thiazolidinedione (TZD) that is currently available in Europe. During the last few years, the focus has been on the sideeffect profile of this group of medications. In 2007, following a meta-analysis by Nissen et al. [1] on the cardiovascular safety of rosiglitazone, it was shown that rosiglitazone was associated with cardiovascular risk in terms of increased risk of myocardial infarction (MI). Further to this, the US Food and Drug Administration (FDA) have given strict criteria for new prescriptions and additional warning labeling for rosiglitazone. The European Medicine Agency (EMA) has withdrawn the marketing authorization for rosiglitazone. Of late, concerns have also been raised regarding a possible link between pioglitazone use and bladder cancer [2-4]. Here, the authors review the risk-benefit profile of pioglitazone, with a 
particular focus on the putative link between pioglitazone and bladder cancer.

\section{METHODS}

English language articles were included in the literature search, including the key terms "pioglitazone," "bladder cancer," and "type 2 diabetes." The literature search included clinical trials, preclinical trials, and epidemiology and evidence reviews.

\section{PIOGLITAZONE AND CARDIOVASCULAR OUTCOME}

Following concerns regarding the cardiovascular safety of rosiglitazone, the effect of pioglitazone on cardiovascular outcomes has been closely evaluated in recent years. Even though they belong to the same class, unlike rosiglitazone, pioglitazone has a favorable cardiovascular outcome.

A meta-analysis of 19 trials comparing pioglitazone with placebo or active comparator in 16,390 patients with diabetes has shown that pioglitazone was associated with a significantly lower risk of death, MI, or stroke [5]. Death, MI, or stroke occurred in 375 out of 8,554 patients (4.4\%) on pioglitazone therapy as compared to 450 of 7,836 patients $(5.7 \%)$ receiving controlled therapy [hazard ratio $(\mathrm{HR})=0.82$; 95\% CI, 0.72-0.94; $P=0.005]$.

In the PROspective pioglitAzone Clinical Trial In macroVascular Events (PROactive) study, the primary composite endpoint (mortality, nonfatal MI, silent MI, stroke, acute coronary syndrome, endovascular or surgical intervention on the coronary or leg arteries, major leg amputation) analysis failed to show a beneficial effect for pioglitazone [6]. The HR for primary composite endpoint was 0.904 in favor of pioglitazone (95\% CI, 0.80-1.08; $P=0.095$ ).
For the primary endpoint, the 3-year placebo event rate was $23.5 \%$ and the pioglitazone event rate was $21 \%$ (relative risk reduction of $10 \%$ ); the number needed to treat (NNT) to prevent one cardiovascular event was 120 per year [6-9]. The prespecified main secondary endpoint was death, MI, and stroke. Analysis of the main secondary endpoint has shown a significant benefit for pioglitazone $(\mathrm{HR}=0.84 ; 95 \% \mathrm{CI}$, $0.722-0.981 ; P=0.027)$. For the main secondary endpoint (placebo event rate $13.6 \%$ and pioglitazone event rate $11.6 \%$ ), NNT was 143 per year. Furthermore, the statistical significance is lost only when revascularization procedures are included within the primary composite endpoint. In other words, when commonly used cardiovascular outcomes (death, MI, or stroke) are evaluated, the statistically significant beneficial effect of pioglitazone is revealed. A further subgroup analysis of the PROactive study (PROactive 05) looked at the effect of pioglitazone on recurrent MI in 2,445 patients with diabetes and previous MI [8]. This showed that patients treated with pioglitazone had a statistically significant beneficial effect on the prespecified endpoint of fatal and nonfatal MI $(P=0.045 ; 28 \%$ relative risk reduction) which translates into an estimated NNT of approximately 149 per year and acute coronary syndrome $(P=0.035 ; \quad 37 \%$ risk reduction $)$ compared with those treated with placebo.

Two other studies which looked at the effect of pioglitazone on the progression of atherosclerosis have also shown a favorable outcome. Carotid artery intima media thickness (CIMT) is a surrogate marker for cardiovascular disease. A study comparing the effect of pioglitazone versus glimepiride on changes in CIMT in type 2 diabetes patients has shown that over an 18-month period, pioglitazone slowed progression of CIMT compared with glimepiride [10]. In the 
Prospective Evaluation of a RIsk Score for postoperative pulmonary COmPlications in Europe (PERISCOPE) study, coronary intravascular ultrasonography (IVUS) was used to assess the change in percent atheroma volume in patients with type 2 diabetes and coronary artery disease, and the study compared pioglitazone with glimepiride [10]. In total, 360 patients completed the final IVUS assessment at 18 months, which showed that pioglitazone-treated patients had a significantly lower rate of progression of coronary atherosclerosis, compared with patients treated with glimepiride. Both these studies have used surrogate markers to assess the effect of pioglitazone on atherosclerosis, which has shown that the pioglitazone slows the progression of atherosclerosis compared to an active comparator (sulfonylurea).

In summary, pioglitazone appears to be associated with potential cardiovascular outcome benefits (Table 1) [5-10].

\section{HEART FAILURE}

Heart failure is the most commonly recognized side effect of pioglitazone. TZDs cause fluid retention and peripheral edema, predisposing the susceptible patients to heart failure. No detrimental effect on left ventricular function has been shown with TZDs. The pioglitazone meta-analysis revealed that serious heart failure was reported in 200 (2.3\%) of pioglitazone-treated patients, compared with 139 (1.8\%) of the control patients $\quad(\mathrm{HR}=1.41 ; \quad 95 \% \quad \mathrm{CI}, \quad 1.14-1.76$; $P=0.002$ ), but the composite endpoint of death and serious heart failure was not statistically different in the two groups [5]. The data from the PROactive study specifically looking at pioglitazone use and heart failure (PROactive 08) also showed a significant increase in heart failure in pioglitazone-treated patients, but subsequent analysis of patients who developed serious heart failure has shown that the all-cause mortality was proportionately lower with the pioglitazone group $(40 / 149 ; 26.8 \%)$ compared with the placebo group $(37 / 108 ; 34.3 \%)(P=0.1338)$ [7]. The composite endpoint of death, nonfatal MI, or stroke was much less in pioglitazone patients with serious heart failure (34.9\%) compared with placebo (47.2\%), which was statistically significant $(P=0.025)$.

\section{PIOGLITAZONE AND BLADDER CANCER}

Experimental studies have reported that peroxisome proliferator-activated receptor (PPAR) agonists like pioglitazone and dual PPAR gamma/PPAR alpha agonists like muraglitazar induce urothelial bladder tumors [12]. Initial studies suggested that this is a ratspecific phenomenon [11]. Two mechanisms were postulated for this phenomenon. Urothilium has plenty of PPAR gamma receptors, and direct interaction of the agonist with the receptors ultimately leading to induction of cancer was one possible mechanism suggested. But it has been shown that even though the PPAR gamma expression was at similar levels in rat and mouse urothelium, the TZD produced bladder tumors only in the rat and not in the mouse. In-vitro studies using human urothelial cell lines have shown that PPAR gamma agonists inhibit cell proliferation, hence a direct carcinogenic effect to the urothelium by the PPAR gamma agonist is less likely [11]. Also, as PPAR agonists are highly lipophilic, only a small percentage of administered drugs get excreted in the urine, reducing the exposure of the drug to the urothelium. The second postulated mechanism involves alteration to the urinary composition leading to cytotoxicity, necrosis, and urothelial 


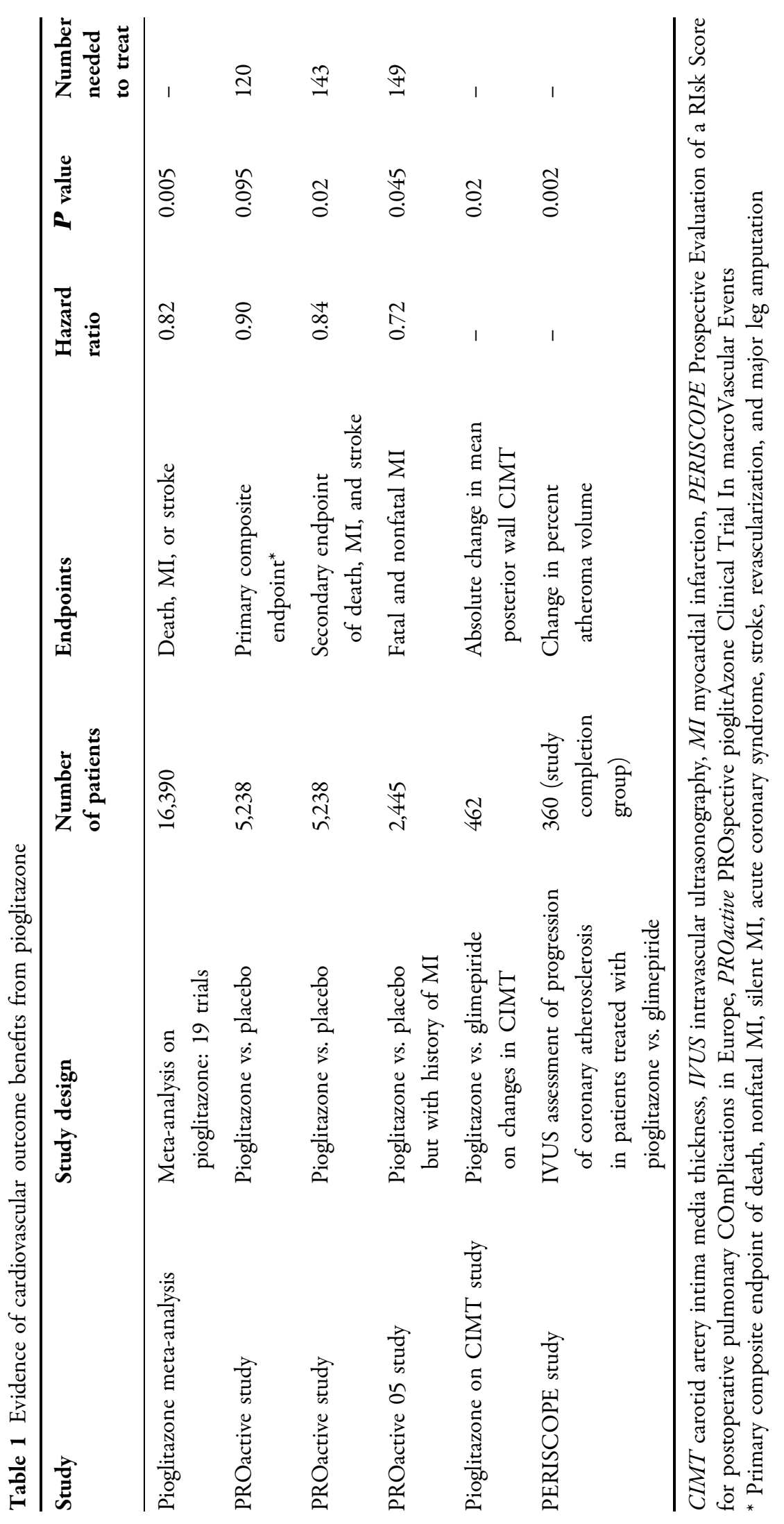


proliferation. Studies have shown that both PPAR gamma agonists and PPAR gamma/PPAR alpha agonists alter urinary composition, resulting in calcium containing urinary solids to varying degrees [11]. This is associated with increased urothelial injury, necrosis, and regenerative proliferation. The amount of urinary solids detected in rats treated with pioglitazone was less than that observed for rats treated with muraglitazar [11]. As expected, muraglitazar induced a significantly higher incidence of bladder tumors than the small number induced by pioglitazone. The evidence from experimental studies supports the hypothesis that potential cytotoxicity may be related to urinary solids, namely calcium containing crystals and calculi [11].

An interim report of a longitudinal cohort study conducted between 1997 and 2002, that assessed the risk of bladder cancer among diabetic patients treated with pioglitazone (including 193,099 patients in the Kaiser Permanente Northern California Diabetes Registry, $>40$ years of age) showed that after adjusting for age, sex, tobacco use, and use of other categories of diabetes medications, there was no significant increase in the risk of bladder cancer in patients ever exposed to pioglitazone, compared with patients never exposed to pioglitazone ( $\mathrm{HR}=1.2 ; 95 \% \mathrm{CI}, 0.9-1.5)$, with similar results in men and women [12]. However, the risk of bladder cancer rose with increasing duration of pioglitazone use. Compared to never being used, pioglitazone treatment for more than 24 months was associated with a $40 \%$ increase in relative risk of developing bladder cancer $(\mathrm{HR}=1.4 ; 95 \% \mathrm{CI}$, 0.9-2.1). Based on these data, the FDA calculated that duration of therapy longer than 12 months was associated with 27.5 excess cases of bladder cancer per 100,000 person-years follow-up, compared with no use of pioglitazone [13].
More recently, Piccinni et al. [14] have reported further evidence for the association of pioglitazone use and bladder cancer after analyzing the data from the FDA's drug adverse event reporting system. They retrieved data regarding drug adverse events concerning antidiabetic medications between 2004 and 2009. The association between antidiabetic drugs and bladder cancer was analyzed by case/non-case methodology using reporting odds ratio (ROR) as a measure of disproportionality. Overall, 93 reports of bladder cancer were retrieved, corresponding to 138 drug reaction pairs (obtained by splitting co-medications and multiple reactions reported for each case). The ROR for bladder cancer was 4.3 for pioglitazone (95\% CI, 2.82-6.52; $P<0.001)$. The ROR for gliclazide was 3.56 (95\% CI, 1.42-8.39) and for acarbose it was 5.12 (95\% CI, 1.0-14.33). With the number of bladder cancer cases reported with gliclazide and acarbose being small, it is too susceptible to reporting biases, and hence not clinically relevant. But this report concluded that there was a definite signal for bladder cancer associated with pioglitazone use [11].

A retrospective cohort study using the data from the French National Health Insurance System also showed an increased risk of bladder cancer with pioglitazone use [12]. This study was from a cohort of 1,491,060 diabetes patients on drug therapy, aged 40-79, followed-up for up to 4 years (2006-2009). Of these, 155,535 patients were pioglitazone treated. The results showed that after adjusting for age, sex, and use of other antidiabetic medications, there was a statistically significant increase in the risk of bladder cancer in patients exposed to pioglitazone, compared with patients exposed to other antidiabetic agents $(\mathrm{HR}=1.22 ; 95 \% \mathrm{CI}, 1.03-1.43)$. The results also showed a dose effect related to cumulative dose $>28,000 \mathrm{mg}(\mathrm{HR}=1.75 ; 95 \%$ 
CI, 1.22-2.5) and for exposure longer than 1 year (HR $=1.34 ; 95 \% \mathrm{CI}, 1.02-1.75)$. A significant increase in risk was observed in males $(\mathrm{HR}=1.28 ; 95 \% \mathrm{CI}, 1.09-1.51)$ [13]

\section{FRACTURE RISK}

TZDs affect the bone homeostasis adversely. Mesenchymal stem cells in the bone act as the common progenitor of both adipocytes and osteoblasts [15]. TZD alters the maturation of mesenchymal stem cells. This affects the bone density and osteoblast functioning, which leads to reduced osteoblast activity, shifting the balance of bone homeostasis to favor bone loss.

Clinical studies have shown an increased risk of fractures, especially in females. In the PERISCOPE study, fractures occurred in 3\% of patients treated with pioglitazone, compared with none in the glimepiride group [7].

An analysis of the clinical trial database of the pioglitazone manufacturer with a special focus on fractures has shown an excess risk in female patients [16]. There was no increased risk of fracture identified in men. The majority of fractures observed in female patients who received pioglitazone were in the distal upper limb (forearm, hand, and wrist) or distal lower limb (foot, ankle, fibula, and tibia). The calculated fracture incidence was 1.9 per 100 patient-years in the pioglitazone-treated group and 1.1 fractures per 100 patient-years in the comparator treated group, resulting in an excess fracture risk of 0.8 fractures per 100 patientyears of pioglitazone use [16].

\section{REGULATORY CONSIDERATIONS FOR PIOGLITAZONE}

Following the retrospective study conducted by the National Health Insurance Agency, the French agency for drug regulations (AFSSAPS) have suspended the use of pioglitazone in France since June 2011 [17].

The FDA safety communication in June 2011 announced that the use of pioglitazone for more than 1 year may be associated with an increased risk of bladder cancer [13]. It recommended not to use pioglitazone in patients with active bladder cancer, and to evaluate risks and benefits before initiating pioglitazone [3]. The FDA encourages physicians to counsel patients regarding the symptoms of bladder cancer [3].

In July 2011, the EMA concluded that the evidence from different sources showed a small increased risk of bladder cancer with pioglitazone, in particular in patients treated for the longest durations and with the highest cumulative doses [2]. The EMA advised the clinicians not to use pioglitazone in patients with a past or current history of bladder cancer or in patients with uninvestigated macroscopic hematuria. Various risk factors for bladder cancer (elderly people, smoking, previous exposure to occupational risk factors, or drugs related to a risk of bladder cancer) should be assessed before initiating pioglitazone. The balance of risk and benefits should be assessed before as well as during treatment with pioglitazone, to ensure that only patients who are deriving sufficient benefit continue to take it.

\section{CONCLUSION}

Pioglitazone remains a useful blood glucoselowering therapy and may produce significant clinical benefits for some patients, particularly from the perspective of potential cardiovascular outcomes. It would therefore be inappropriate to recommend discontinuation of pioglitazone use for all patients. A number of safety concerns have been identified with pioglitazone, including an increased risk of cardiac failure, bone fracture, and a small but definite increase 
in the risk of bladder cancer. Thus, when considering the use of pioglitazone, an individualized patient risk-benefit evaluation is essential with the use of pioglitazone being inappropriate in people considered at risk of bone fracture, cardiac failure, or bladder cancer.

\section{ACKNOWLEDGMENTS}

All authors meet the International Committee of Medical Journal Editors (ICMJE) guidelines for contribution to this manuscript. Dr. Evans and Dr. Govindan contributed equally to the writing of the manuscript, review, and interpretation of the referenced data. There are no competing financial or commercial interests for either Dr. Evans or Dr. Govindan with respect to this manuscript. Dr. Evans has received research awards, speaker fees, and has served as an advisor for Novo Nordisk, sanofi-aventis, Novartis, Eli Lilly, MSD, and GSK. Dr. Evans is the guarantor for this article, and takes responsibility for the integrity of the work as a whole.

Open Access. This article is distributed under the terms of the Creative Commons Attribution Noncommercial License which permits any noncommercial use, distribution, and reproduction in any medium, provided the original author(s) and source are credited.

\section{REFERENCES}

1. Nissen SE, Wolski K. Effect of rosiglitazone on the risk of myocardial infarction and death from cardiovascular causes. N Engl J Med. 2007;356: 2457-71.

2. European Medicines Agency position statement on Pioglitazone. European Medicines Agency. Available at: http://www.ema.europa.eu/docs/en GB/document_library/Press_release/2011/07/WC50 0109176.pdf. Accessed Sept 282012.
3. Rosiglitazone maleate (marketed as Avandia, Avandamet, and Avandaryl) Information. U.S. Food and Drug Administration. Available at: http:// www.fda.gov/Drugs/DrugSafety/PostmarketDrugSafety InformationforPatientsandProviders/ucm143349.htm. Accessed Nov 122011.

4. European Medicines Agency recommends suspension of Avandia, Avandamet and Avaglim. European Medicines Agency. Available at: http:// www.ema.europa.eu/ema/index.jsp?curl=pages/news_ and_events/news/2010/09/news_detail_001119.jsp\& $\mathrm{mid}=\mathrm{WCOb01ac058004d5c1 \& murl=menus/news}$ and_events/news_and_events.jsp\&jsenabled=true. Accessed Jan 52012.

5. Lincoff AM, Wolski K, Nicholls SJ, Nissen SE. Pioglitazone and risk of cardiovascular events in patients with type 2 diabetes mellitus: a meta- analysis of randomized trials. JAMA. 2007; 298:1180-8.

6. Dormandy JA, Charbonnel B, Eckland DJ, et al. Secondary prevention of macrovascular events in patients with type 2 diabetes in the PROactive Study (PROspective pioglitAzone Clinical Trial In macro Vascular Events): a randomised controlled trial. Lancet. 2005;366:1279-89.

7. Betteridge J, DeFronzo RA, Chilton RJ. PROactive: time for a critical appraisal. Eur Heart J. 2008;29: 969-83.

8. Erdmann E, Dormandy JA, Charbonnel B, et al. The effect of pioglitazone on recurrent myo-cardial infarction in 2,445 patients with type 2 diabetes and previous myocardial infarction: results from the PROactive (PROactive 05) Study. J Am Coll Cardiol. 2007;49:1772-80.

9. Mazzone T, Meyer PM, Feinstein SB, et al. Effect of pioglitazone compared with glimepiride on carotid intima-media thickness in type 2 diabetes: a randomized trial. JAMA. 2006;296:2572-781.

10. Nissen SE, Nicholls SJ, Wolski K, et al. Comparison of pioglitazone vs glimepiride on progression of coronary atherosclerosis in patients with type 2 diabetes: the PERISCOPE randomized controlled trial. JAMA. 2008;299:1561-73.

11. Suzuki S, Arnold LL, Pennington KL, et al. Effects of pioglitazone, a peroxisome proliferator-activated receptor gamma agonist, on the urine and urothelium of the rat. Toxicol Sci. 2010;113: 349-57.

12. Lewis JD, Ferrara A, Peng T, et al. Risk of bladder cancer among diabetic patients treated with pioglitazone: interim report of a longitudinal cohort study. Diabetes Care. 2011;34:916-22. 
13. Drug Safety and Avialability. US Food and Drug Administration. Available at: http://www.fda.gov/ Drugs/DrugSafety/UCM266555.htm. Accesed 24 Jan 2012.

14. Piccinni C, Motola D, Marchesini G, Poluzzi E. Assessing the association of pioglitazone use and bladder cancer through drug adverse event reporting. Diabetes Care. 2011;34:1369-71.

15. Riche DM, King ST. Bone loss and fracture risk associated with thiazolidinedione therapy. Pharmacotherapy. 2010;30:716-27.

16. Takeda Pharmaceuticals North America. Observation of an increased incidence of fractures in female patients who received long-term treatment with ACTOS (pioglitazone $\mathrm{HCl}$ ) tablets for type 2 diabetes mellitus (Letter to Health Care Providers), March 2007. Available at: http://www. fda.gov/Safety/MedWatch/SafetyInformation/Safety AlertsforHumanMedicalProducts/ucm150451.htm. Accessed Jan 4, 2012.

17. AFSSAPS: Position statement: use of medications containing pioglitazone suspended. AFSSAPS. Available at: http://www.afssaps.fr/Infos-de-securite/ Communiques-Points-presse/Suspension-de-l-utili sation-des-medicaments-contenant-de-la-pioglita zone-Actos-R-Competact-R-Communique. Accessed Sept 282011. 